\title{
A PROCESS THEORY ON TRANSFORMATION OF WORK THROUGH INTERNAL CROWDSOURCING
}

\begin{abstract}
Internal crowdsourcing showed a substantial increase of use in recent years, since it describes a promising alternative to traditional orchestration of employees in today's digital era. However, literature falls short in explaining the transformation process that is enacted by such approaches of platform-based work organization. By using a work organizational perspective with the existing body of knowledge in combination with a revelatory case study, this paper develops a process theory explaining the transformation process of internal crowdsourcing over time and how the organization of work transform during this process. Moreover, we discovered four different forms of organizing work with a completely new form of work organization: the "Hybrid Flash Organization". Scholars can identify critical incidents and process phases, while practitioners use our findings as a transformation guideline of internal crowdsourcing to detect potential threads, opportunities and constraints along the way of a successful implementation.
\end{abstract}

\section{Keywords:}

internal crowdsourcing, process theory, flash organization, new work organization 


\section{INTRODUCTION}

Internal crowdsourcing showed a substantial increase of use in recent years (Durward \& Blohm, 2018; Palacios, Martinez-Corral, Nisar, \& Grijalvo, 2016), since it describes a promising alternative to traditional orchestration of employees in today's digital era with a change in technology, increasing job automation and new forms of employment. For instance, Bosch launched an internal crowdsourcing platform inviting its employees to join the crowd in order to create a logistics dictionary. Through internal crowdsourcing, the company could integrate employees from all over the globe that reflected the whole supply chain. As a result, Bosch was able to globally synchronize these definitions for the first time in its history (Zuchowski, Posegga, Schlagwein, \& Fischbach, 2016). However, building up and orchestrating such a huge crowd reflects a major transformation for any organization that does not happen automatically. The case of the Allianz Group UK illustrates the dilemma. The company introduced an internal crowdsourcing platform for idea generation in order to drive innovation. While the initial setup of the platform was comparably easy, it took the organization almost eight years to entirely integrate the work performed on this platform into its business operations due to magnitude of change that was required (Hind \& Leidner, 2016).

Existing research (Hind \& Leidner, 2016; Malhotra, Majchrzak, Kesebi, \& Looram, 2017; Simula \& Ahola, 2014; Stieger, Matzler, Chatterjee, \& Ladstaetter-Fussenegger, 2012) has focused so fare on the examination of internal crowdsourcing as a complex socio-technical work system (Lyytinen \& Newman, 2008). These studies have made great strides in understanding the potentials of internal crowdsourcing as new mode of work organization (Ågerfalk \& Fitzgerald, 2008), different application domains (Malhotra et al., 2017) as well as the design of the individual components that are needed to build such systems (Vukovic, 2009). However, this research falls short in explaining the transformation process that is enacted by such approaches of platform-based work organization (Afuah \& Tucci, 2012). The 
conceptualization of internal crowdsourcing as a socio-technical system is very well suited to describe a static situation of a work organization and the underlying work systems and other fine-grained components. Consequently, this perspective is inherently static in nature.

Internal crowdsourcing as organizational innovation is a process that uses IT to enact a change process of work organization (Zuchowski et al., 2016). Extending this argumentation, the conceptualization of internal crowdsourcing as an organizational innovation process suggests one major shortcoming of existing research. The successful implementation of internal crowdsourcing as platform-based approaches of work organization, requires an active process of change management. However, an understanding of such approaches is missing in current research. This knowledge would support a better understanding of the transformation process by having solutions at disposal to roll it out. Moreover, it enables informed decision-making in organizations concerning using internal crowdsourcing (Leicht, Blohm, \& Leimeister, 2017). In order to understand the process of internal crowdsourcing and the corresponding drivers and effects of internal crowdsourcing as novel mode of work organization (Zhao \& Zhu, 2014a; Zuchowski et al., 2016), it is necessary to illuminate the surrounding organizational and environmental context (Langley \& Truax, 1994; Pettigrew, 1990). Particularly, it is pivotal to look beyond specific events, decisions and activities that drive internal crowdsourcing within organizations and how they enact the transformation of work organization. Thus, our research is driven by the question of how does internal crowdsourcing affect the organization of work over time?

This paper develops a process theory that explains the transformation process when organizations strive towards internal crowdsourcing as a new mode of work organization. In so doing, we overcome existing research that considers internal crowdsourcing as a static sociotechnical system (Zuchowski et al., 2016). We broaden this view by re-conceptualizing internal crowdsourcing as an organizational innovation, combining the basis of the static socio-technical 
system with current research on internal crowdsourcing to obtain a theoretical construct that allows to describe the dynamic effects of the transformation of work organization.

In a second step, we use these dimensions within the framework of an empirical process theory, which we develop on the basis of a large scale qualitative case study of SwissBank - one of the leading Swiss commercial banks that has introduced internal crowdsourcing over a period of almost four years. Alongside of the development of our process theory, we present the transformation in work organization and how they are affected by the specific events, decisions activities during the internal crowdsourcing journey of SwissBank.

This paper is structured as follows: In section 2, the characteristics of work organization and internal crowdsourcing are worked out. Followed by the theoretical background of STS theory in combination with internal crowdsourcing in section 3. In section 4 we outline our methodology. This is followed by the presentation of our results. Finally, theoretical and practical implications, as well as prospective areas for future research of this paper, are highlighted.

\section{CONCEPTUAL BACKGROUND: INTERNAL CROWDSOURCING}

The idea of crowdsourcing is that a crowdsourcer, e.g., a company, proposes to an undefined group of contributors or crowd workers (individuals, formal or informal teams, other companies) the voluntary undertaking of a task presented in an open call (Blohm et al., 2013). Crowdsourcing provides several benefits such as broader access to specialized skills (Prpić, Shukla, Kietzmann, \& McCarthy, 2015), more flexible and faster hiring processes (Kuek, Paradi-Guilford, Fayomi, Imaizumi, Ipeirotis, Pina et al., 2015), shorter product development cycles (Simula \& Ahola, 2014) or lower costs (Schenk \& Guittard, 2011). A crowdsourcer can apply crowdsourcing externally or inside its organizational boundaries. Early crowdsourcing initiatives started within the external setting, where contributors participate in some sort of digital freelancing. Today, companies increasingly use their own employees as an internal 
crowd of contributors in order to leverage collective intelligence or to orchestrate their employees more efficiently (Zuchowski et al., 2016).

Internal crowdsourcing counter various effects that a work organization has to deal with. While environmental factors influencing the organizational structure (Geiger \& Schader, 2014), firms can apply internal crowdsourcing to transform their organization of work by allowing to reform their work system arrangement beyond former organizational boundaries (Kittur, Nickerson, Bernstein, Gerber, Shaw, Zimmerman et al., 2013; Lang, Bharadwaj, \& Di Benedetto, 2016). Through internal crowdsourcing employees capture existing distributed knowledge and resources, while new capabilities are added to the organization through testing and implementing the new mode of work organization (Lopez, Vukovic, \& Laredo, 2010). The move from a decision-centric (van Oorschot, Akkermans, Sengupta, \& Van Wassenhove, 2013) to a dynamic and flexible work environment, requires an organization to overcome the disparity of the actual work mode and the desired state (Deng \& Joshi, 2016; Skopik, Schall, \& Dustdar, 2010). And, implement the defined processes and structures to enable and facilitate the new work mode. Since, knowledge and capabilities have the propensity to be accumulated or adjusted over time (Majchrzak \& Malhotra, 2016), the crowdsourcing performance improves with the respective knowledge and experience accumulation of the crowd. Through the collaborative approach of internal crowdsourcing by integrating all stakeholders the acquired organizational knowledge is used for improvements to the design of the crowdsourcing platform, for a more efficient, flexible and adaptable working environment (Stieger et al., 2012) or to cultivate a collaborative culture of innovation at the organization (Afuah \& Tucci, 2012; Geiger \& Schader, 2014; Lenart-Gansiniec, 2017; Levine \& Prietula, 2014). The integrative system and feedback structure in internal crowdsourcing (Elia \& Margherita, 2018), allows organization to continuously monitor the crowd's performance, responses and output in order 
to detect any potential issues regarding the system as well as the distribution, allocation, and integration of crowd's tasks and workers. Or to put in other words internal crowdsourcing is a new form of work organization, which allows organizations to continuously reform their way to divide labor and integrate effort for organizational and individual output performance.

\section{THEORETICAL BACKGROUND: A WORK ORGANIZATIONAL PERSPECTIVE ON INTERNAL CROWDSOURCING}

Depending on how the boundaries of a work organization are defined, a product or service can represent a complete ensemble of activities in a stand-alone system or it can be composed of different partial results of interdependent partial work systems of a larger work organization (Sinha \& Van de Ven, 2005). A work organization thus consists of different work systems of different size and function for the completion of a certain task. The efficiency of the underlying work organization involves choices about work design, technology, people, rewards, layout or information flows (Parker, Van den Broeck, \& Holman, 2017). Following the idea of optimization, at an organizational level, productivity is the most ostensible outcome, which is usually measured by the number of products made, sales achieved or product quality. However, in today's context of increasingly demanding and powerful customers, customer satisfaction and innovation are likely to assume greater importance to assess the productivity and success of work organizations.

Internal crowdsourcing is a new form of work organization. The platform-based orientation of internal crowdsourcing restructures the distribution of work and the allocation of employees in the organization. In this form of work organization, the involved work systems are usually conceptualized as a complex socio-technical system (Geiger \& Schader, 2014; Knop, Durward, \& Blohm, 2017). According to socio-technical systems (STS) theory, every work system is made up of a social system (people, structure) and a technical system (technology, tasks) to produce a good or service for customers (Bostrom \& Heinen, 1977; 
Lyytinen \& Newman, 2008). The STS perspective is useful for analyzing digital work organizations (such as internal crowdsourcing) and underlying work systems, and enables to capture the associated transition from one work organization or underlying system to another (e.g., Mumford, 2006; Sykes, Venkatesh, \& Johnson, 2014).

The social system of internal crowdsourcing consists of the organizational actors and the organizational structure in which the actors interact with each other and the components of the technical system. The participating actors (crowdworker and crowdsourcer) in internal crowdsourcing are embedded in this social system and influence with their participation the functionality and usefulness of the underlying work and information system (Baxter \& Sommerville, 2011). In contrast to traditional work systems, internal crowdsourcing connects employees or crowd workers not according to position profiles, but on the basis of solving a given task. This type of work system creates an ad-hoc work system whose purpose is defined by the solution of a specific task. As a result, employees must constantly integrate themselves into new types of ad-hoc organizations, which consist of constantly changing online collaborators. Due to voluntary nature of participation, also the motivational concept changes from being rather driven by extrinsic motivation, such as traditional payment, to intrinsic motivation (Zhao \& Zhu, 2014b). First empirical results suggest that working in internal crowdsourcing systems is a very new experience for employees. The transformation from traditional work organization, where colleagues and direct supervisors are personally known to each other, to platform-based oriented work with changing responsibilities and work routines leads to a new acquisition of competencies by employees and a changed organizational work structure (Durward, Blohm, \& Leimeister, 2016; Zuchowski et al., 2016). In opposition to "traditional" work settings, there is no direct supervisor, because managers of the internal crowdsourcing system have no managerial authority towards the crowd. These differences in vertical hierarchy of traditional work compared to horizontal hierarchy of internal 
crowdsourcing changes the communication to a more democratic and egalitarian pattern of structuring the organization of work (Zuchowski et al., 2016).

In the technical system of internal crowdsourcing is according to the STS theory not just an information systems that allow to organize a large number of employees to perform work (Lyytinen \& Newman, 2008). The crowdsourcing platform also enables the use of fast and efficient technology-based tools for task communication executions, such as work assignment, evaluation and feedback. Therefore, in internal crowdsourcing, all communication and interaction are digitally mediated via the crowdsourcing platform. Thus, participating employees have to build up new digital communication channels, learn how to collaborate in this new environment and must also adapt to a dynamic coordination between allocated tasks and to a different styles of receiving feedback (Blohm, Leimeister, \& Krcmar, 2013; Zuchowski et al., 2016). Due to the dynamic and decentralized mode of work overcoming departmental boundaries, internal crowdsourcing provides employees with a diverse task range in a higher frequency (Gaspoz, 2011; Hind \& Van Alstyne, 2010; Leicht, Blohm, \& Leimeister, 2016).

Given these tremendous changes, internal crowdsourcing addresses with the reconceptualization of the social- and technical-system two fundamental problems of a work organization: how to divide work and how to integrate effort.

Dividing work includes task division, with the problem of translating the objectives of the work organization into tasks and subtasks, and the task allocation, with mapping the tasks obtained through task division to work systems or individual employees. The integrating effort includes ensuring the collaboration effort, which refers to the problem of mapping a set of implicit or explicit mechanisms to employees to ensure their motivation to perform the assigned work tasks, and coordination effort, which provides employees with the information they need to perform their tasks and coordinate their activities with others (Parker et al., 2017; Puranam, Alexy, \& Reitzig, 2014). The organizational decisions on organizing work with the division of 
work and the integration of effort create, at the organizational level the organization's design, operations, and culture (Foss \& Klein, 2014; Schneider, Ehrhart, \& Macey, 2013), on the individual level, individual work designs in which employees have assigned tasks and responsibilities. The overall design of the work organization has significant impact on the organizational as well as on individual or team outcomes.

Thus, when organizations make transform the way of organizing work, such as internal crowdsourcing, the introduction of such a new approach reflects a transformation process that influences the division and allocation of tasks to employees as well as the coordination and collaboration effort of the organization.

We focus on the organizational level of work organization and how task division, task allocation, collaboration effort and coordination effort effect an organization when striving towards internal crowdsourcing. Consequently, following the work organization approach allows to describe the utilization of internal crowdsourcing and takes account for the understanding of work organization and for examining the changing nature of organizing work over time, across levels, modules and systems and the influencing social- and technical system (see Figure 1).

Insert Figure 1 about here.

\section{METHODOLOGY}

The objective of our process study is to analyze and understand the process of transformation in the organization of work through the introduction of internal crowdsourcing. We view the transformation of a work organization towards internal crowdsourcing as a process consisting of different work organizations which internalize different compositions of organizing work tasks. We want to investigate, which work organizations arise from the 
introduction of internal crowdsourcing and which events, decisions and activities influence the transformation to a new work organization and how this work organization is characterized by the division of work and the integration of effort. To achieve this objective, we use a qualitative research approach with semi structured interviews for our longitudinal case study. A qualitative research approach allows data to be collected in natural settings and ultimately offers rich and holistic insights through local groundedness (Miles, Huberman, \& Saldaña, 2014). It is especially well-suited to capture events, decisions and activities and thus represents an adequate way of analyzing the transformation from one work organization to another (Miles et al., 2014). Within our longitudinal case-study, we conducted 31 semi-structured. For the analysis of the interviews, we employed a multi-staged, inductive coding approach based on Gioia, Corley, and Hamilton (2013) and a temporal bracketing strategy proposed by Langley (1999).

\section{Case selection}

To develop our understanding, we developed a process theory that describes how the transformation process of internal crowdsourcing changed the way of task division and allocation as well as coordination and collaboration effort of an organization over time. A process theory is well suited for explaining and predicting organizational change and the transition from "traditional work" settings into new modes of work organization. We follow a process ontology in which we consider processes as a constantly changing phenomenon whose transformation are shaped by organizational events and the experiences of the participating actors (Langley, Smallman, Tsoukas, \& Van de Ven, 2013).

As internal crowdsourcing reflects a complex arrangement of work organizational dimensions that involve various information systems and various contingencies at the individual- and organizational level, we follow a case and process research strategy (Benbasat, Goldstein, \& Mead, 1987; Langley et al., 2013). The specific research design as a single case study involves data collection at the organizational level within one case firm (Siggelkow, 2007; 
Yin, 2013). The case site, referred to here as SwissBank, became accessible as a longitudinal empirical account of an internal crowdsourcing implementation in software testing. Over four years, the organization complemented its centralized software testing structure with a decentralized intra-organizational testing structure including more than 200 employees that participated in software testing on a weekly base. More specifically, SwissBank had been developing a new business software, which should become the core business software, for years and struggled with the extensive regulatory testing demands. In order to accomplish the testing in the required quality and the project's stretched timeline, SwissBank included its employees in software testing.

SwissBank thus offered a unique opportunity for both a "critical" and a "revelatory" longitudinal case study (Yin, 2013) for investigating how the transformation process of internal crowdsourcing unfolds over time within one organization. The case of SwissBank is well-suited for developing our intended process theory for three reasons. First, the implementation of the internal crowdsourcing project was initiated by executives in order to build up innovative competences in software testing and transforming the existing work structures. Second, the project was at a large scale and significantly affected a broad range of business units over a long period of time. Third, software testing is a complex knowledge task that is executed in a very regular fashion and requires a sophisticated orchestration process for the involved business units and stakeholders.

\section{Data Collection}

Qualitative research has a long and honorable history, particularly in terms of its ability to be revelatory (Guba \& Lincoln, 1994), and to handle large amounts of longitudinal process data (Langley, 1999; Miles, Huberman, Huberman, \& Huberman, 1994; Pettigrew, 1990; Van de Ven \& Huber, 1990). Since decades, researchers have used qualitative data in order to inductively develop theories. Qualitative research and content analyses, thus, does not test 
hypotheses about reality, but rather attempts to expand institutional theory, to elucidate the complex social processes involved (Eisenhardt \& Graebner, 2007) and to interpret reality (Suddaby, 2006). This approach is best used when no explicit hypothesis is to be tested (Martin $\&$ Turner, 1986) and where researchers have an interesting phenomenon without explanation and from which they seek to "discover theory from data" (Suddaby, 2006).

Two main sources of data were used: First, we conducted interviews with all stakeholders of the internal crowdsourcing project (see Table 1), and second, we collected pertinent documents. The interviewees, as first data source, included organizational executives and other stakeholders playing an important role in the internal crowdsourcing process (e.g., project managers, software testing managers, crowd workers and other project participants). We conducted 31 semi-structured interviews in four waves (see Table 1). Interviews lasted between 30 and 90 minutes and were either conducted via telephone and Skype calls or faceto-face meetings. The interviews were transcribed, coded and analyzed by using the analysis software Nvivo 12. In addition, documents were consulted in order to triangulate interview data including strategic planning documents, company presentations, newspaper articles, web articles, guidelines and correspondence.

For the initial phase of developing the interview protocol, we followed Kvale (1996) and designed an open-ended interview guideline in order to ensure that our semi-structured interview approach (Myers \& Newman, 2007) elicited relevant information that allows for tracking the evolution of internal crowdsourcing until the specific time of the interview as accurately as possible. To start our understanding of the longitudinal process towards the organization of work with internal crowdsourcing, we conducted an initial analysis after the first wave of interviewing to identify major decisions, activities and events with in the evolution of internal crowdsourcing at SwissBank. This initial analysis led to some adjustment in the focus of data collection for the second, third and fourth waves - a fairly normal occurrence in 
inductive research (Eisenhardt \& Graebner, 2007). Interview schedules for the following phases were more closely adapted to different project stages and the transition points between them. The purpose was to generate at first a large amount of process data and trace developments to the last data collection point, to refine, link and validate the information obtained earlier and to follow the ongoing processes as far as possible. To achieve this, the following phases of interviewing continued between November 2016 and September 2019. Once all the data had been collected, a detailed descriptive chronology of the case was prepared and wherever possible, submitted to the original informants for verification.

Insert Table 1 about here.

\section{Data Analysis}

To systematically extract the transformational process towards internal crowdsourcing and analyze how the work organization changes their composition of dividing and allocating tasks as well as coordinating and collaborating effort, we coded the interviews. Codes "are labels that assign symbolic meaning to the descriptive or inferential information compiled during a study"(Miles et al., 2014: 71). They can be used to retrieve and categorize chunks of information in interview transcripts to cluster segments that relate to a particular construct or theme (Miles et al., 2014). In our case, the codes serve to structure the verbalizations of the transformational work organization process from the interviews. We use these codes to derive distinct transition points from one work organization to another in the transformational process towards internal crowdsourcing and analyze these different arrangements of work organization based on how they dividing and allocating tasks as well as coordinating and collaborating effort. We followed a data analysis and coding approach proposed by Gioia et al. (2013), which is well established in related literature on work organization and process research(e.g. Langley et al. (2013); Langley and Truax (1994)). We conducted the approach of (Gioia et al., 2013) in two 
waves. First, we explorative analyzed the data to derive different events, decisions and activities, which occurred during the introduction of internal crowdsourcing. And, in a second wave we deductively analyzed the data to derive how these events, decisions and activities influenced the way tasks are divided and allocated as well as the effort for coordinating and collaborating work. The approach of Gioia et al. (2013) is based on a multi-staged coding scheme with first-order codes, second-order concepts, and aggregated dimensions.

First-order codes represent informant-centric terms that emerge during the interviews. For these codes, we adhered to words that were used by the participants of the internal crowdsourcing system during the interviews to describe implementation of internal crowdsourcing and the work organization at this stage. Based on similarities and differences in these codes, it is possible to derive second-order concepts that represent germane themes and categories described during the interviews (Gioia et al., 2013). These second order concept "help us to describe and explain the phenomena we are observing"(Gioia et al., 2013: 20). Finally, it is possible to aggregate these second-order concepts to distinct phases of work organization in internal crowdsourcing and extract the relevant changes on dividing and allocating tasks as well as coordinating and collaborating effort at theses phases. Table 2 provides an extract of the coding scheme. To increase confidence in the analysis, two researchers were involved in the coding process. We followed Saldaña (2015), who notes that coding "can and should be a collaborative effort" (p. 27) to develop more objective perspective on the codes and their interpretation. For this purpose, literature suggests an iterative process of "constant comparison"(Corbin \& Strauss, 1990). In line with Saldaña (2015)) and Harry, Sturges, and Klingner (2005), we did not attempt to develop a numerical reliability rating, but to reach a consensus on the appropriate usage of the set of codes. We developed potential concepts and dismissed, changed, or retained them based on comparisons across the interviews to achieve a coherent synthesis. We discussed preliminary results and variations and gave our 
raw data to independent students for analysis (cf. Lehrig, Krancher, \& Dibbern, 2017). We adapted the concepts whenever suitable or necessary. In this way, we embarked on "a process of testing the codes for clarity and reliability"(Harry et al., 2005: 6).We repeated the process until we reached consensus with regard to the aggregated phases of work organization in internal crowdsourcing and the relevant changes on dividing and allocating tasks as well as coordinating and collaborating effort at theses phases

As outlined earlier, different forms of work organization are emerging during the process of introducing internal crowdsourcing. To examine such work organization based on the codes, we followed a temporal bracketing strategy proposed by Langley (1999). It represents a standard approach for analyzing process data and is especially well-suited for an “open-ended inductive approach that most researchers use in process research"(Langley et al., 2013: 693). At its core, temporal bracketing refers to the "decomposition of data into successive adjacent periods [which] enables the explicit examination of how actions of one period lead to changes in the context that will affect action in the subsequent periods"(Langley, 1999: 703). That is, based on the codes (aggregated phases), we reconstructed the transformational work organization processes, by which different activities, decisions and events lead to a different form of organizing work. These processes can then be grouped based on the number of transitions between phases and similarities in their alignment to describe the processes as “evolving work organizations"(Langley, 1999). Figure 2 shows a visual representation of the process results with influencing events, decisions and activities occurred during the introduction of internal crowdsourcing.

Insert Table 2 about here.

This flow-chart, drawn from our case, incorporate in themselves an intermediate level of theorizing between the raw data and a more abstract and theoretical process model (Gioia et 
al., 2013) and thus is an essential part of demonstrating rigor in qualitative research (Pratt, 2008; Tracy, 2010).

\section{RESULTS}

In this section, we present the results of our process theory. Based on the initial situation at SwissBank, we highlight the different decisions, activities and events relating to four different work organizations. In each of the four work organizations, we present the changes that have taken place in the task division, allocation as well as the coordination, collaboration effort of the respective work organizations.

\section{Initial Situation before introducing Internal Crowdsourcing}

SwissBank, a Swiss-based bank with over 9000 employees in over 850 branches, initiated the project in 2014 to implement a new enterprise software. The new software, as proposed by the bank, would enable SwissBank to increase productivity and significantly reduce operational costs for administration, maintenance and training. Due to the internal structure of the bank with independent institutes, the project developed over time to be extremely complex and cost-intensive for two major reasons. First, considerable data protection regulations had to be complied with, and second, inter-company consistency, analysis and control mechanisms had to be established. The project budget therefore had to be adjusted several times and finally reached several hundred million Swiss francs. After two years of development, the bank was faced with the challenge of complying with the test regulations of the regulatory authorities on the one hand and creating appropriate personnel structures on the other in order to be able to carry out these tests successfully. In detail, Swiss Bank's IT department was strongly hierarchically organized with clear decision-making authority and processes. The IT department's test process was characterized by the quantitative processing of clear pre-defined test cases at a central location, i.e., SwissBank's headquarters, by specifically trained IT testers. This procedure was not suitable for the quantity and quality of the minimum 
requirements required by the regulatory authorities. In order to support the project, it was decided to involve employees in the testing process.

\section{The Transformational Process enacted by Internal Crowdsourcing}

In the following, we describe SwissBank transformational process towards a new organization of work through internal crowdsourcing (see Figure 1).

Insert Figure 1 about here.

Project Organization. The starting point for SwissBank's transformational process, reflected a project organization which is characterized by a clearly defined time frame and resource allocation and that the work is organized and designed according to clearly defined goals to develop a software solution. The specific decisions, activities and events (see Figure 1) are oriented to pursue the primary goal of SwissBank to integrate internal crowdsourcing into this existing project organization.

Events: The first event that triggered the internal crowdsourcing project in the first place, was extensive requirement for software tests of the new banking software, which the regulatory authorities had imposed on SwissBank. SwissBank was therefore under extreme pressure to meet the audit requirements imposed by the regulatory authorities and was aware about the current state of general infrastructure and organizational processes at the SwissBank with limited resources.

Decisions: Triggered by this event, the executives of SwissBank made two central decisions towards the implementation of internal crowdsourcing. First, to acquire new external expertise to find a solution in a tandem with crowdsourcing experts and the IT department to positively influencing the process by translating the internal crowdsourcing vision to a clear proposal for change. Due to time pressure and lengthy procurement processes, SwissBank managers decided not to invest in additional test software and supporting equipment. The 
limited resources of IT employees and time pressure, resulted, in the decision to leverage the expertise of all organizational employees to execute the testing of the new enterprise software, and to begin with a crowdsourcing trial and the initiation for a crowdsourcing environment. Correspondingly, the employees who wants to get involved because of potential experience and expertise could apply for specific testing purposes.

Activities: For the success of internal crowdsourcing, communication plays a significant role in guiding employees towards a common goal (Chatzimilioudis, Costa, Zeinalipour-Yazti, \& Lee, 2017; Lauto, 2013). Hence, SwissBank introduced new roles and responsibilities, e.g., administrative crowdsourcing managers. These new roles are needed to develop a system for testing the software, but also to cultivate a common understanding and shared long-term vision. The corresponding processes were defined and worked out, how the results from the crowd workers testing efforts should be used in the overarching project. Three measures were taken. First, an in-depth due-diligence to uncover testing needs and rapid prototyping options for possible crowdsourcing approaches. Second, the determination of a proper implementation and exit timeline with necessary resources. As a last step, roles, rights and responsibilities were defined for the crowdsourcing system. Three new roles for specific tasks were created at SwissBank, (1) the Product Development Officer (PMO) supervises the overall development of elements of the new enterprise software, (2) the software testmanager responsible for the software testing and (3) crowdworker tests of the software. Another critical decision was to redesign the existing infrastructure to facilitate decentralized testing through internal employees over the crowdsourcing platform. After defining and setting up the crowdsourcing workflow, the employees were invited by the organization over the newly implemented crowdsourcing system. After the engagement phase with crowd workers and the allocation to specific crowdsourcing tasks, the crowdsourcing project was scaled up by the organization. 
Change in Work Organization: At the project organization, the problem and outcome are defined at a broad level including the analysis with resource justification. In order to establish the new form of work coordination, the project organization developed a roadmap, which must be adhered to by all stakeholder. The time context and corresponding resources are determined in order to achieve the defined goal. Specific internal crowdsourcing processes are defined and developed as well as the resource distribution are planned, e.g., role definition of new job profiles. The task allocation took place in a top-down structure. There is a clear and fixed task division based on the respective competencies, skills and responsibilities of the workers variation as well as a clear vertical work coordination of communication. In the separate hierarchical levels, the various work systems coordination effort only takes place on the same level. The other hierarchical levels and the respective work systems are not integrated until tasks have been completed and coordinated. The overall organization of work in the project organization is to create a framework in which the pre-defined goals can be achieved in time and the corresponding fixed structural processes and tasks can be performed with the necessary efficiency and quality.

Business Process Organization. The transition from the "project organization" to a "business process organization" is made by implementing and rolling out the emerged processes and structures for internal crowdsourcing within SwissBank's organizational infrastructure. The goal at this stage is to work through the defined processes according to clearly pre-defined procedures and to analyze the first wave of software testing results of the crowdworkers. It is also the transition point, where the work organization shifts into a new form of work organization with streamlined task responsibilities, accumulated first knowledge in process flow and the integration of outside expertise (see Figure 1).

Events: The decision in the project organization not to invest in new infrastructure has now shown that the existing IT infrastructure and software solutions, were not completely suitable 
for decentralized work organization enacted by internal crowdsourcing. Therefore, when SwissBank integrated the internal crowdsourcing into the full work organization, it experienced low performance (number of completed software tests, slow IT system performance) and extensive administrational effort (allocation of tasks, evaluation of software testing results) through the existing infrastructure. In addition, the discrepancy between the task requirements and the expertise of the crowdworker as well as the repetitive character of the tasks have demotivated the crowd and reduced the quality of the crowdsourcing system.

Decisions: SwissBank decided to provide comprehensive crowdsourcing guidelines with all necessary information, feedback and clear structural and procedural support systems for PMOs, test managers and crowdworkers in order to support a successful integration and give employees the opportunity to acquire the necessary knowledge and internalize the requirements in self-study. The aim was to create a common knowledge base within the workforce and to introduce a consistent standard for working in the internal crowdsourcing system.

Activities: Designing an overarching standardized work organization that describes the process on how single crowdsourcing tasks are performed within the system was key for the success of the project and motivation of the crowd worker. Once the testing community for the specific crowdsourcing tasks was established, software testing began on a weekly basis. Correspondingly, effective modes and mechanisms were developed for providing concise feedback and support towards crowd worker about work and task performance. After tasks got allocated to the crowd workers, managers of SwissBank needed to raise awareness and force action through reminders and escalation, due to the lack of attention or misdirection to maintain efficiency of the system.

Change in Work Organization: After the integration of the internal crowdsourcing processes, SwissBank can be regarded as a "business process organization". The structures, processes, technology and knowledge base defined in the Project Organization were adopted and 
integrated throughout the organization. With the introduction of internal crowdsourcing as a new way of organizing work, all employees were made available for the first time, and all task, competencies, skills and responsibilities of employees were allocated via the self-developed crowdsourcing platform.

The decentralized work coordination of the software testing followed the integrated and standardized structures and procedures. Nevertheless, established procedures, processes and standards are reproduced by the participants, and elements in the organizational crowdsourcing structure are gradually refined, e.g., strengthening the IT infrastructure. This work organization is characterized by incremental and cumulative changes. In particular, the new structure of task allocation and work coordination results does not yet function seamlessly. However, a big difference to the project organization is the first attempt to break up the existing hierarchical logic of SwissBank. The work collaboration was positively influenced by the feedback systems installed between the individual hierarchical levels. This input enabled a quick absorption of problems and increased work coordination capabilities across hierarchical boundaries and different work systems. The changes in work coordination and collaboration increased the amount of delivered testing and the performance of the overall internal crowdsourcing system. Particularly, from a quality perspective, the first improvements are made, which are attributed to the standardized work execution within the testing and the accumulated knowledge handling the testing. The changeover from the business process organization towards a new form of work organization is the disaggregation of the existing structure of the current internal crowdsourcing work organization in order to capture the experience made by introducing and working with internal crowdsourcing, in order to build modular knowledge that can then be transferred into different crowdsourcing work contexts. 
Knowledge Organization. Developed from the "Business Process Organization" in the knowledge organization the modularization of existing knowledge enabled the SwissBank to flexible adapt and re-orchestrate its capabilities based on the modules created from reproducible processes and best-practice knowledge.

Events: The test results show a discrepancy between the amount of work done and the quality of the test results between traditional, experienced test teams and the crowd workers. This happened because the tasks were not assigned to the expertise of the crowdworkers and the traditional test teams had a longer experience with the test cases. In addition, communication between the crowd workers, their direct supervisor and the testmanagers was asynchronous and reduced the efficiency of the crowdsourcing system. This became apparent at this stage of the development after investigating the reasons for the difference in performance between crowd workers and traditional testing teams. In some cases, the employees received wrong or misleading feedback and thus no improvement of the work results occurred.

The software receives final approval from the authorities. This is a crucial event, as the original objective of introducing internal crowdsourcing has been achieved and the further use of internal crowdsourcing within SwissBank must be questioned.

Decisions: Due to the success of the previous internal crowdsourcing project, SwissBank decided to use internal crowdsourcing for further areas of work in the organization. All employees were therefore invited to join an organizational crowdsourcing community in order to make use of the knowledge gained and the established structures for the organization. The employees can integrate themselves into specialized expert teams in the crowdsourcing community in order to establish specific or complementary expertise within the crowdsourcing community for further work assignments. This decision enables SwissBank to divide and allocate tasks according to the best fit of expertise and skills of these expert teams. 
Activities: Through feedback of crowd workers and administrational employees, the previous developed processes and structures at SwissBank got evaluated and redesigned. Therefore, the allocation of crowd workers towards the right tasks and monitoring their output was necessary and challenging as well as the evaluation a high amount of crowd contributions and identifying the valuable contributions.

Change in Work Organization: Interacting dynamics create pressure on the existing structure, leading to re-orientation of the organizational work mode at SwissBank. This happens through influencing events, decisions and activities on the organizational structure, e.g., through crowd worker feedback, the development of new testing journeys and/or aggregation of specific competences through crowdsourcing teams (see Figure 1). The decision to invite and group all crowdsourcing actors in the crowdsourcing system to expert teams, enables SwissBank to make a wider use of internal crowdsourcing. The work organization changed from a solely task division and allocation focus, where the only premise is the optimization of completed work orders, towards a "knowledge organization", where the focus lies on the operationalization of coordinating work task to the best existing knowledge in the organization bundled based in the crowdsourcing community. The emerged mode of work organization is able to transfer the expert knowledge and structure into a different context and work systems by restructuring their capabilities within the existing structure. The internalized processes for an improved task division and allocation, which originated in the business process organization, are used at this stage to generate synergies through a better interlocking of the individual work systems (e.g., expertise from other crowdsourcing projects). 
Hybrid-Flash Organization: In the last step of the crowdsourcing project at SwissBank, the enterprise software was finally tested and all regulatory requirements were fulfilled. The highest valued benefit for SwissBank was not only the approved and stable new banking software but also to discover a completely new mode of work organization by restructure the knowledge and integrate it into a stand-alone crowdsourcing center. The crowd workers gained early experience of the new business software and had the opportunity to give input to increase the usability and improve the software they will have to use in the future.

Events: Further divisions of SwissBank want to use expertise of the crowd via the crowdsourcing system for further projects within the organizational boundaries of SwissBank.

Decisions: The organization released resources in terms of crowdworkers, but left the structural and administrative infrastructure intact. During the project SwissBank discovered, that the concept of crowdsourcing could be of high value for various projects and established a competence center for further crowdsourcing projects within the organization. SwissBank offered the crowd workers to stay into the crowdsourcing community in order to engage in future projects.

Change in Work Organization: At this stage, the work organization of SwissBank transformed from a knowledge organization towards a hybrid form of a flash organization. A flash organization is defined as an work organization, which establish only formal structures and mechanisms to coordinate work towards crowd workers or teams as an independent work organization without specify and defining all processes and actions (Valentine, Retelny, To, Rahmati, Doshi, \& Bernstein, 2017). Once the software-testing project was completed, SwissBank transferred the acquired knowledge into formal structures of a system (in our case a competence center) with an independent character. The creation of a hybrid form of a flash organization derived through the fact, that SwissBank as a work organization uses the advantage of "asset specifity" in the work collaboration between employees. Asset specifity is the value 
that comes from employees collaborate together over time (Valentine et al., 2017). The combination is made possible, through internal crowdsourcing, where tasks or allocated towards "temporally stable" ad-hoc work systems with relevant expert knowledge and experience to the given task. Through the community effect and the existing ties between the crowd workers in teams and the formal structure of the flash organization, SwissBank developed a "Hybrid Flash Organization". This new emerged organization of work is able to rapidly assemble and coordinate its crowdworker by organizing and initiating a community of potential crowdworker or teams to processing complex task within the work organizational needs.

The organization of work is characterized in the hybrid flash organization by a high skill variety where different skills, knowledge and talents are required from the crowd worker. And, a high task identity by committing over the community to the project with their expertise being a value part in the social system and of the work outcome. Through the established feedback systems, the crowd worker receives detailed task related information and guideline about their work, which they perform autonomous over the crowd-work platform in the technical system of the organization.

\section{IMPLICATIONS}

In this paper, we have developed a process theory which identifies four different forms of work organization and the associated change of work division and allocation as well as collaboration and coordination effort. We show that at the beginning a Project Organization is created which follows the approaches of existing research and analyses existing structures in the organization to strengthen a common work culture. The existing infrastructure necessary for internal crowdsourcing was analyzed and appropriate measures and processes were defined to enable platform supported work. From the moment of the consolidation of structures and the extension of internal crowdsourcing to the entire work organization, a Business Process 
Organization is created. This organization of work implements the processes defined in the Project Organization to the entire organization and further consolidates them. The transition point in this organization is the generation of new employee competencies to perform more complex tasks. Competencies in the Knowledge Organization could be reassigned to new area of expertise via the crowdsourcing platform, thus enabling more complex work tasks to be handled by the internal crowd. The turning point in the Hybrid Flash Organization, was the possibility to bundle the gained experience and expertise within the Hybrid Flash Organization and to rapidly create ad-hoc expert work systems via the crowdsourcing community to handle complex work tasks or projects throughout the organization.

Insert Table 3 about here.

\section{Theoretical Implications}

We have developed a process theory over a longitudinal case study, which describes the evolutionary aspect of introducing internal crowdsourcing into an existing work organization. By looking at the development and introduction of a new form of division of labor and work integration we can derive two theoretical implications.

First, research in crowdsourcing and related platform-based work systems has made great strides in the last decade (Bailey \& Horvitz, 2010; Leicht et al., 2017; Malhotra et al., 2017; Vukovic, 2009). While, existing internal crowdsourcing research has focused on the development of mechanisms and individual aspects of the technical design of crowdsourcing platforms, and their potential benefits and shortcomings (Hind \& Leidner, 2016; Malhotra et al., 2017; Zuchowski et al., 2016). The findings presented, complement this knowledge by showing in a process study how the individual aspects interlock in an end-to-end implementation. With the identification of the four different work organization we are going well beyond the results of existing research (Jette, Breck, \& Johns, 2015; Lopez et al., 2010; 
Prpić et al., 2015; Simula \& Ahola, 2014). Over the four phases of work organization, we show the development of different skills and capabilities and how these skills and capabilities lead to new organizational competences for executing complex work tasks.

Our research also shows how internal crowdsourcing can transform an existing work organization and go beyond the largely used form of a pure innovation or micro task platforms (Deng \& Joshi, 2016; Malhotra et al., 2017). Our process theory shows critical incidents and process phases in our case organizations that may change the perception of such novel modes of work organization. Moreover, our work does extend existing research (Deng \& Joshi, 2016; Zuchowski et al., 2016) in regards to the understanding and management of internal crowdsourcing by showing how internal crowdsourcing unfolds over time and how different events, decisions and activities influence the division of work and integration effort on various hierarchical levels. In the process theory presented, we were also able to observe the development of new skills and capabilities of employees, which have developed through interaction with the new form of work organization. This development of new organizational capabilities was made possible and visible by using internal crowdsourcing as a new way of organizing complex work tasks. Furthermore, we are able to show in the process study that internal crowdsourcing penetrates existing hierarchical structures and lead to a flatter organizational hierarchy in the company.

Second, in previous research, internal crowdsourcing has been mostly considered a static socio-technical system within the boundaries of an organization that cannot account for the associated organizational changes (Zuchowski et al., 2016). We addressed these shortcomings by re-conceptualized internal crowdsourcing as organizational innovation that enacts a transformation process and developing a process theory for platform-based work transformation in organizations showing the different states of work organization when introducing internal crowdsourcing. This new view provides an entirely new perspective on 
platform-based work that has been neglected so far in existing research (Anya, 2015; Zuchowski et al., 2016). In this regard, internal crowdsourcing is a dynamic procedure that influences the nature and the structure of organizing work.

However, we found that the dimensions of dividing and allocating work as well as coordinating and collaborating effort were not the optimal composition to ensure an optimal work organization. In the course of time and through the four different forms of work organization this deficit was overcome. Our research can therefore complement existing research (Knop \& Blohm, 2018; Stewart, Huerta, \& Sader, 2009) by showing how the division of labor and work integration has developed and which critical phases exist. And, how internal crowdsourcing and the presented work organizations follow a combination of different triggering events, decisions and activities that initiate and enforce organizational change development. Furthermore, we show how feedback structures not only penetrate hierarchical structures but also increase employee job satisfaction, which may change the perception of such novel ways of working.

\section{Practical Implications}

Our research results will help companies to successful manage the transformational process from traditional work organization towards platform-based form of work organization like internal crowdsourcing. The outlined research has the following implications for practitioners. On the one hand, our presented process study can be used in companies to better predict possible developmental steps and thus be helpful for the implementation of a new work organization.

Practitioner can use our findings as a transformation guideline of internal crowdsourcing to detect potential threads, opportunities and constraints along the way, and can take over the different decisions, events and activities to ensure a successful implementation of internal crowdsourcing for organizing work. The concept of the presented "Hybrid- Flash 
Organization" as an independent work organization in the corporate environment can be used by companies to perform critical and complex work tasks in-house, to involve employees in the development of new products, services or critical company projects or to train and educate employees. In addition, the findings on division of labor and work integration from the process study are helpful for companies with regard to the successful execution of internal crowdsourcing. The findings are also helpful for companies that new organizational capabilities, the better acquisition and utilization of employee knowledge and expertise can be gained through the introduction of internal crowdsourcing. Therefore, through the developed process theory organizations can manage the implementation of internal crowdsourcing more effectively and efficiently. In addition, our case of SwissBank shows the high relevance of new work organization for both sustaining and creating a culture of innovation as well as the development of agile capabilities in a changing organizational environment.

\section{CONCLUSION, LIMITATIONS AND FUTURE RESEARCH}

This paper presented the unique case of SwissBank, we identified in a qualitative longitudinal case study four different working modes emerged by using internal crowdsourcing. While the first model followed a complete hierarchical top-down structure of a "project organization", the following organizational work mode of a "business process organization" organizational tested the introduced structure and processes on validity and incrementally transformed the system. In the "Knowledge Organization", insights generated in previous steps are disassembled, aggregated and modularized. The nascent organizational structure is restructured and transferred to build what we introduced as a "Hybrid Flash Organization". An organization, which facilitates the advantages of Flash Organizations by organizing crowdworker or teams into an organization, and by reversing the disadvantage of asset specificity into an advantage by using existing crowd skilled employees. We therefore extended our internal crowdsourcing framework to create a holistic and indulgent understanding of 
internal crowdsourcing processes, for which several authors have been calling (Fayard, Gkeredakis, \& Levina, 2016; Knop \& Blohm, 2018; Zuchowski et al., 2016).

Although our case study provides first evidence for the new organization of work with internal crowdsourcing, our results needs to be replicated in additional case studies and/or quantitative research. Moreover, our results could be biased due the fact of SwissBank being considered as an extreme form of internal crowdsourcing. Thus, our findings may vary in other crowdsourcing settings. While the emerging process theory rather focuses on the organizational level and describes how organizations may master the transformation processes, a prospective area for future research may aim to gain a deeper understanding of the perception of this transformation process by employees. Especially, the co-evolutionary impact from crowdworker on the development of new work modes could be examined. Based on our prior work, additional quantitative data from affected employees could be collected in a series of surveys to shed lights in new prospective areas.

\section{REFERENCES}

Afuah, A. \& Tucci, C. L. 2012. Crowdsourcing As a Solution to Distant Search. Academy of Management Review, 37(3): 355-375.

Ågerfalk, P. J. \& Fitzgerald, B. 2008. Outsourcing to an unknown workforce: Exploring opensurcing as a global sourcing strategy. MIS quarterly, 32(2): 385-409.

Anya, O. 2015. Bridge the gap!: What can work design in crowdwork learn from work design theories?, Proceedings of the 18th ACM Conference on Computer Supported Cooperative Work \& Social Computing: 612-627: ACM.

Bailey, B. P. \& Horvitz, E. 2010. What's your idea?: a case study of a grassroots innovation pipeline within a large software company, Proceedings of the SIGCHI Conference on Human Factors in Computing Systems: 2065-2074: ACM.

Baxter, G. \& Sommerville, I. 2011. Socio-technical systems: From design methods to systems engineering. Interacting with Computers, 23(1): 4-17.

Benbasat, I., Goldstein, D. K., \& Mead, M. 1987. The case research strategy in studies of information systems. MIS quarterly: 369-386.

Blohm, I., Leimeister, J. M., \& Krcmar, H. 2013. Crowdsourcing: how to benefit from (too) many great ideas. MIS Quarterly Executive, 12(4): 199-211.

Bostrom, R. P. \& Heinen, J. S. 1977. MIS problems and failures: A socio-technical perspective. Part I: The causes. MIS quarterly: 17-32. 
Chatzimilioudis, G., Costa, C., Zeinalipour-Yazti, D., \& Lee, W. C. 2017. Crowdsourcing emergency data in non-operational cellular networks. Information Systems, 64: 292302.

Corbin, J. M. \& Strauss, A. 1990. Grounded theory research: Procedures, canons, and evaluative criteria. Qualitative sociology, 13(1): 3-21.

Deng, X. N. \& Joshi, K. D. 2016. Why Individuals Participate in Micro-task Crowdsourcing Work Environment: Revealing Crowdworkers' Perceptions. Journal of the Association for Information Systems, 17(10): 648-673.

Durward, D., Blohm, I., \& Leimeister, J. M. 2016. Crowd Work. Business \& Information Systems Engineering, 58(4): 281-286.

Durward, D. \& Blohm, I. 2018. Understanding Job Satisfaction of Crowd Workers: An Empirical Analysis of Its Determinants and Effects. Paper presented at the Multikonferenz Wirtschaftsinformatik (MKWI), Lüneburg, Germany.

Eisenhardt, K. M. \& Graebner, M. E. 2007. Theory building from cases: Opportunities and challenges. Academy of Management Journal, 50(1): 25-32.

Elia, G. \& Margherita, A. 2018. Assessing the maturity of crowdventuring for corporate entrepreneurship. Business Horizons, 61(2): 271-283.

Fayard, A. L., Gkeredakis, E., \& Levina, N. 2016. Framing Innovation Opportunities While Staying Committed to an Organizational Epistemic Stance. Information Systems Research, 27(2): 302-323.

Foss, N. J. \& Klein, P. G. 2014. Why managers still matter. MIT Sloan Management Review, 56(1): 73 .

Gaspoz, C. 2011. Prediction Markets as Web 2.0 Tools for Enterprise 2.0, Americas Conference on Information Systems (AMCIS 2011).

Geiger, D. \& Schader, M. 2014. Personalized task recommendation in crowdsourcing information systems - Current state of the art. Decision Support Systems, 65: 3-16.

Gioia, D. A., Corley, K. G., \& Hamilton, A. L. 2013. Seeking qualitative rigor in inductive research: Notes on the Gioia methodology. Organizational research methods, 16(1): $15-31$.

Guba, E. G. \& Lincoln, Y. S. 1994. Competing paradigms in qualitative research. Handbook of qualitative research, 2(163-194): 105.

Harry, B., Sturges, K. M., \& Klingner, J. K. 2005. Mapping the process: An exemplar of process and challenge in grounded theory analysis. Educational researcher, 34(2): 3-13.

Hind, B. \& Van Alstyne, M. W. 2010. How to find answers within your company. MIT Sloan Management Review, 52(2): 66-77.

Hind, B. \& Leidner, D. 2016. Harnessing Employee Innovation in Internal Crowdsourcing Platforms: Lessons from Allianz UK. Paper presented at the International Conference on Information Systems (ICIS 2016), Dublin, Ireland.

Jette, A., Breck, A., \& Johns, R. 2015. Integrating Balanced Scorecard Performance Management with Crowdsourced Strategic Planning. Paper presented at the Proceedings of the Transportation Research Board Annual Meeting, Washington DC, USA. 
Kittur, A., Nickerson, J. V., Bernstein, M., Gerber, E., Shaw, A., Zimmerman, J., Lease, M., \& Horton, J. 2013. The future of crowd work. Paper presented at the Proceedings of the 2013 conference on Computer supported cooperative work - CSCW '13.

Knop, N., Durward, D., \& Blohm, I. 2017. How to Design an Internal Crowdsourcing System. Paper presented at the International Conference on Information Systems (ICIS 2017), Seoul, South Korea.

Knop, N. \& Blohm, I. 2018. Adaptation Barries in Internal Crowdosurcing: A Multiply Case Study. Paper presented at the European Conference on Information Systems (ECIS 2018), Southhampton, UK.

Kuek, S. C., Paradi-Guilford, C., Fayomi, T., Imaizumi, S., Ipeirotis, P., Pina, P., \& Singh, M. 2015. The global opportunity in online outsourcing: The World Bank.

Kvale, S. 1996. Interviews as knowledge construction, International Journal of Psychology, vol. 31: 2711-2711: PSYCHOLOGY PRESS 27 CHURCH RD, HOVE, EAST SUSSEX, ENGLAND BN3 2FA.

Lang, M., Bharadwaj, N., \& Di Benedetto, C. A. 2016. How crowdsourcing improves prediction of market-oriented outcomes. Journal of Business Research, 69(10): 41684176.

Langley, A. \& Truax, J. 1994. A process study of new technology adoption in smaller manufacturing firms. Journal of Management Studies, 31(5): 619-652.

Langley, A. 1999. Strategies for Theorizing from Process Data. Academy of Management Journal, 24(4): 691-710.

Langley, A., Smallman, C., Tsoukas, H., \& Van de Ven, A. H. 2013. Process Studies of Change in Organization and Management: Unveiling Temporality, Activity, and Flow. Academy of Management Journal, 56(1): 1-13.

Lauto, G. V., Finn; Hatzack, Frank; Carlsen, Maria. 2013. Managing Front-End Innovation through Idea Markets at Novozymes : Idea Markets Stimulate Creativity and Enable Recombination of Existing Knowledge in Large Corporations. Research Technology Management, 56(4): 17-26.

Lehrig, T., Krancher, O., \& Dibbern, J. 2017. How Users Perceive and Actualize Affordances: An Exploratory Case Study of Collaboration Platforms.

Leicht, N., Blohm, I., \& Leimeister, J. M. 2016. How to Systematically Conduct Crowdsourced Software Testing? Insights from an Action Research Project. Paper presented the International Conference on Information Systems (ICIS 2016), Dublin, Ireland.

Leicht, N., Blohm, I., \& Leimeister, J. M. 2017. Leveraging the Power of the Crowd for Software Testing. IEEE Software, 34(2): 62-69.

Lenart-Gansiniec, R. 2017. Virtual Knowledge Sharing in Crowdsourcing: Measurement Dilemmas. Journal of Entrepreneurship Management and Innovation, 13(3): 95-123.

Levine, S. S. \& Prietula, M. J. 2014. Open Collaboration for Innovation: Principles and Performance. Organization Science, 25(5): 1414-1433.

Lopez, M., Vukovic, M., \& Laredo, J. 2010. People Cloud Service for Enterprise Crowdsourcing. World Conference on Services: 686-692.

Lyytinen, K. \& Newman, M. 2008. Explaining information systems change: a punctuated sociotechnical change model. European Journal of Information Systems, 17(6): 589-613. 
Majchrzak, A. \& Malhotra, A. 2016. Effect of Knowledge-Sharing Trajectories on Innovative Outcomes in Temporary Online Crowds. Information Systems Research, 27(4): 685703.

Malhotra, A., Majchrzak, A., Kesebi, L., \& Looram, S. 2017. Developing Innovative Solutions Through Internal Crowdsourcing. MIT Sloan Management Review, 58(4): 73-79.

Martin, P. Y. \& Turner, B. A. 1986. Grounded theory and organizational research. The journal of applied behavioral science, 22(2): 141-157.

Miles, M. B., Huberman, A. M., Huberman, M. A., \& Huberman, M. 1994. Qualitative data analysis: An expanded sourcebook: sage.

Miles, M. B., Huberman, A. M., \& Saldaña, J. 2014. Qualitative data analysis: A methods sourcebook. 3rd: Thousand Oaks, CA: Sage.

Mumford, E. 2006. The story of socio-technical design: Reflections on its successes, failures and potential. Information Systems Journal, 16(4): 317-342.

Myers, M. D. \& Newman, M. 2007. The qualitative interview in IS research: Examining the craft. Information and organization, 17(1): 2-26.

Palacios, M., Martinez-Corral, A., Nisar, A., \& Grijalvo, M. 2016. Crowdsourcing and organizational forms: Emerging trends and research implications. Journal of Business Research, 69(5): 1834-1839.

Parker, S. K., Van den Broeck, A., \& Holman, D. 2017. Work Design Influences: A Synthesis of Multilevel Factors That Affect the Design of Jobs. Academy of Management Annals, 11(1): 267-308.

Pettigrew, A. M. 1990. Longitudinal field research on change: Theory and practice. Organization science, 1(3): 267-292.

Pratt, M. G. 2008. Fitting oval pegs into round holes: Tensions in evaluating and publishing qualitative research in top-tier North American journals. Organizational Research Methods, 11(3): 481-509.

Prpić, J., Shukla, P. P., Kietzmann, J. H., \& McCarthy, I. P. 2015. How to work a crowd: Developing crowd capital through crowdsourcing. Business Horizons, 58(1): 77-85.

Puranam, P., Alexy, O., \& Reitzig, M. 2014. What's "new" about new forms of organizing? Academy of Management Review, 39(2): 162-180.

Saldaña, J. 2015. The coding manual for qualitative researchers: Sage.

Schenk, E. \& Guittard, C. 2011. Towards a characterization of crowdsourcing practices. Journal of Innovation Economics \& Management 1(7): 93-107.

Schneider, B., Ehrhart, M. G., \& Macey, W. H. 2013. Organizational climate and culture. Annual review of psychology, 64: 361-388.

Siggelkow, N. 2007. Persuasion With Case Studies. Academy of Management Journal, 50(1): 20-24.

Simula, H. \& Ahola, T. 2014. A network perspective on idea and innovation crowdsourcing in industrial firms. Industrial Marketing Management, 43(3): 400-408.

Sinha, K. K. \& Van de Ven, A. H. 2005. Designing work within and between organizations. Organization Science, 16(4): 389-408. 
Skopik, F., Schall, D., \& Dustdar, S. 2010. Modeling and mining of dynamic trust in complex service-oriented systems. Information Systems, 35(7): 735-757.

Stewart, O., Huerta, J. M., \& Sader, M. 2009. Designing crowdsourcing community for the enterprise, Proceedings of the ACM SIGKDD Workshop on Human Computation: 5053: ACM.

Stieger, D., Matzler, K., Chatterjee, S., \& Ladstaetter-Fussenegger, F. 2012. Democratizing strategy: How crowdsourcing can be used for strategy dialogues. California Management Review, 54(4): 44-68.

Suddaby, R. 2006. From the editors: What grounded theory is not: Academy of Management Briarcliff Manor, NY 10510.

Sykes, T. A., Venkatesh, V., \& Johnson, J. L. 2014. Enterprise system implementation and employee job performance: Understanding the role of advice networks. Mis Quarterly, 38(1): 51-72.

Tracy, S. J. 2010. Qualitative quality: Eight "big-tent" criteria for excellent qualitative research. Qualitative inquiry, 16(10): 837-851.

Valentine, M. A., Retelny, D., To, A., Rahmati, N., Doshi, T., \& Bernstein, M. S. 2017. Flash organizations: Crowdsourcing complex work by structuring crowds as organizations, Proceedings of the 2017 CHI conference on human factors in computing systems: 3523-3537: ACM.

Van de Ven, A. H. \& Huber, G. P. 1990. Longitudinal field research methods for studying processes of organizational change. Organization science, 1(3): 213-219.

van Oorschot, K. E., Akkermans, H., Sengupta, K., \& Van Wassenhove, L. N. 2013. Anatomy of a Decision Trap in Complex New Product Development Projects. Academy of Management Journal, 56(1): 285-307.

Vukovic, M. 2009. Crowdsourcing for Enterprises. Paper presented at the 2009 Congress on Services - I.

Yin, R. K. 2013. Case Study Research. Design and Methods (6 ed.). Thousands Oaks, CA, USA: Sage Publications.

Zhao, Y. \& Zhu, Q. 2014a. Evaluation on crowdsourcing research: Current status and future direction. Information Systems Frontiers, 16(3): 417-434.

Zhao, Y. C. \& Zhu, Q. 2014b. Effects of extrinsic and intrinsic motivation on participation in crowdsourcing contest. Online Information Review, 38(7): 896-917.

Zuchowski, O., Posegga, O., Schlagwein, D., \& Fischbach, K. 2016. Internal Crowdsourcing: Conceptual Framework, Structured Review, and Research Agenda. Journal of Information Technology, 31(2): 166-184. 
Table 1*

\section{Overview of Interviews}

\begin{tabular}{|c|c|c|c|c|c|}
\hline Wave & Year & $\begin{array}{l}\text { Number of } \\
\text { interviews }\end{array}$ & Type of informants & $\begin{array}{l}\text { Average length } \\
\text { (minutes) }\end{array}$ & Method \\
\hline 1 & 2016 & 8 & $\begin{array}{c}1 \mathrm{ClO}, \\
1 \mathrm{PMO}, \\
2 \text { Crowdworker, } \\
4 \text { Software Test } \\
\text { Managers }\end{array}$ & 30 & $\begin{array}{l}3 \text { face to face } \\
5 \text { skype calls }\end{array}$ \\
\hline 2 & 2017 & 7 & $\begin{array}{c}1 \text { Executive, } \\
3 \text { PMOs, } \\
3 \text { Crowdworkers }\end{array}$ & 28 & 7 face to face \\
\hline 3 & 2018 & 10 & $\begin{array}{c}1 \text { Project Participant, } \\
2 \text { Software Test } \\
\text { Managers, } \\
3 \text { PMOs, } 4 \\
\text { Crowdworkers }\end{array}$ & 47 & $\begin{array}{l}8 \text { skype calls } \\
2 \text { face to face }\end{array}$ \\
\hline 4 & 2019 & 6 & $\begin{array}{c}3 \text { Executive, } \\
3 \text { Project Participants }\end{array}$ & 35 & $\begin{array}{l}4 \text { face to face } \\
2 \text { skype calls }\end{array}$ \\
\hline
\end{tabular}

Table 2*

Excerpt of Coding Scheme (based on Gioia et al. 2013)

\begin{tabular}{|c|c|c|}
\hline $1^{\text {st }}$ Order Codes (Examples) & $\begin{array}{l}2^{\text {nd }} \text { Order } \\
\text { (Examples) }\end{array}$ & $\begin{array}{l}\text { Aggregated } \\
\text { Themes }\end{array}$ \\
\hline $\begin{array}{l}\text { - Definition of problem areas } \\
\text { - Outlining project structure and scope } \\
\text { - Determining requirements of Internal } \\
\text { Crowdsourcing } \\
\text { - Current Testing procedure }\end{array}$ & $\begin{array}{l}\text { - Identification of problem } \\
\text { - Definition of required } \\
\text { resources } \\
\text { - Collection of expertise and } \\
\text { resources }\end{array}$ & $\begin{array}{l}\text { - Project } \\
\text { Organization }\end{array}$ \\
\hline $\begin{array}{l}\text { - Assessing structure to process internal } \\
\text { Crowdsourcing } \\
\text { - Analyzing feedback of employees } \\
\text { - Evaluating first insights generated } \\
\text { - Removing low-quality contributions } \\
\text { - Triangulate information between actors } \\
\text { - Adding context }\end{array}$ & $\begin{array}{l}\text { - Verification of process } \\
\text { structure } \\
\text { - Evolution of integration } \\
\text { - Revision of processes } \\
\text { - Identification of extensions }\end{array}$ & $\begin{array}{l}\text { - Business Process } \\
\text { Organization }\end{array}$ \\
\hline $\begin{array}{l}\text { - Clustering similar developments } \\
\text { - Reducing clusters to overarching topics } \\
\text { - Selecting major change drivers } \\
\text { - Identification of constrains and potentials } \\
\text { - Summarizing results }\end{array}$ & $\begin{array}{l}\text { - Modularization } \\
\text { information } \\
\text { - Aggregation of knowledge } \\
\text { - Selection of insights }\end{array}$ & $\begin{array}{l}\text { - Knowledge } \\
\text { Organization }\end{array}$ \\
\hline $\begin{array}{l}\text { - Sorting the insights } \\
\text { - Discussing the development }\end{array}$ & $\begin{array}{l}\text { - Interpretation } \\
\text { development }\end{array}$ & $\begin{array}{r}\text { - Hybrid-Flash } \\
\text { Organization }\end{array}$ \\
\hline
\end{tabular}




\begin{tabular}{|c|c|c|}
\hline $\begin{array}{l}\text { - Predicting the impact } \\
\text { - Complete exiting project scope } \\
\text { - Starting new organizational development } \\
\text { - Passing results to new organization } \\
\text { - Evaluating structure and processes }\end{array}$ & $\begin{array}{l}\text { - Prediction of project impact } \\
\text { - Assessment of future } \\
\text { benefits } \\
\text { - Definition of current } \\
\text { organizational state }\end{array}$ & \\
\hline $\begin{array}{l}\text { - Identifying information flow } \\
\text { - Communicating test performance } \\
\text { guideline } \\
\text { - Specifying regulatory demands } \\
\text { - Understanding test requirements } \\
\text { - Integrating crowdsourcing platform } \\
\text { - Removing low-quality contributions } \\
\text { - Sorting the insights }\end{array}$ & $\begin{array}{l}\text { - Revision of employee } \\
\text { engagement } \\
\text { - Synchronization of action } \\
\text { - Definition of quality } \\
\text { measures }\end{array}$ & $\begin{array}{l}\text { - Coordination } \\
\text { effort }\end{array}$ \\
\hline $\begin{array}{l}\text { - Communication created roles } \\
\text { - Announcing test results responsibilities } \\
\text { - Performing work autonomous } \\
\text { - Responding to test report } \\
\text { - Identifying misleading information flow } \\
\text { - Summarizing results } \\
\text { - Triangulating information between } \\
\text { stakeholders } \\
\text { - Identifying of constrains and potentials }\end{array}$ & $\begin{array}{l}\text { - Verification of feedback } \\
\text { structure } \\
\text { - Shared understanding } \\
\text { - Open communication } \\
\text { channels } \\
\text { - Conflict and cultural } \\
\text { behavior }\end{array}$ & $\begin{array}{l}\text { - Collaboration } \\
\text { effort }\end{array}$ \\
\hline $\begin{array}{l}\text { - Clustering similar developments } \\
\text { - Determining task constraints } \\
\text { - Reviewing structural test demand } \\
\text { - Verifying task design }\end{array}$ & $\begin{array}{l}\text { - Determination of expertise } \\
\text { - Assessment of crowd skills } \\
\text { - Specification of tasks }\end{array}$ & $\begin{array}{l}\bullet \text { Task } \\
\text { Division }\end{array}$ \\
\hline $\begin{array}{l}\text { - Passing results to new organization } \\
\text { - Assessing current work situation } \\
\text { - Obtaining work approvals } \\
\text { - Checking availability } \\
\text { - Controlling system requirements }\end{array}$ & $\begin{array}{l}\text { - Formalization of hierarchy } \\
\text { - Specification of timeline } \\
\text { - Workload balance } \\
\text { - Prioritization or work } \\
\text { packages }\end{array}$ & $\begin{array}{l}- \text { Task } \\
\text { Allocation }\end{array}$ \\
\hline
\end{tabular}

Table 3*

Summary of Change in Work Organization

\begin{tabular}{|l|l|l|l|l|}
\hline & $\begin{array}{l}\text { Project } \\
\text { Organization }\end{array}$ & $\begin{array}{l}\text { Business } \\
\text { Process } \\
\text { Organization }\end{array}$ & $\begin{array}{l}\text { Knowledge } \\
\text { Organization }\end{array}$ & $\begin{array}{l}\text { Hybrid-Flash } \\
\text { Organization }\end{array}$ \\
\hline $\begin{array}{l}\text { - Task } \\
\text { division }\end{array}$ & $\begin{array}{l}\text { - Task are divided } \\
\text { according to the } \\
\text { job profile }\end{array}$ & & $\begin{array}{l}\text { - Task are } \\
\text { divided } \\
\text { according to } \\
\text { best available } \\
\text { expert team }\end{array}$ & \\
\hline
\end{tabular}




\begin{tabular}{|c|c|c|c|c|}
\hline $\begin{array}{l}\text { - Task } \\
\text { allocation }\end{array}$ & $\begin{array}{l}\text { - Task are allocated } \\
\text { from higher } \\
\text { hierarchies to all } \\
\text { crowd workers }\end{array}$ & $\begin{array}{l}\text { - Task are } \\
\text { allocated } \\
\text { completely } \\
\text { decentralized } \\
\text { over } \\
\text { standardized } \\
\text { crowdsourcing } \\
\text { platform }\end{array}$ & $\begin{array}{l}\text { - Task are } \\
\text { allocated } \\
\text { based on } \\
\text { knowledge } \\
\text { and expertise } \\
\text { rather on load } \\
\text { balancing in } \\
\text { the crowd }\end{array}$ & $\begin{array}{l}\text { Task are } \\
\text { allocated to } \\
\text { ad-hoc work } \\
\text { systems } \\
\text { assembled for } \\
\text { the given task }\end{array}$ \\
\hline $\begin{array}{l}\text { - Coordination } \\
\text { Effort }\end{array}$ & $\begin{array}{l}\text { - Coordination effort } \\
\text { is performed over } \\
\text { new roles and } \\
\text { responsibilities }\end{array}$ & $\begin{array}{l}\text { - Coordination } \\
\text { effort is } \\
\text { performed } \\
\text { decentralized } \\
\text { across } \\
\text { hierarchies and } \\
\text { work systems } \\
\text { over the } \\
\text { crowdworking } \\
\text { platform }\end{array}$ & $\begin{array}{l}\text { - Coordination } \\
\text { effort of expert } \\
\text { teams is } \\
\text { performed } \\
\text { decentral via } \\
\text { the } \\
\text { crowdsourcing } \\
\text { community. }\end{array}$ & $\begin{array}{l}\text { Loose } \\
\text { coordination } \\
\text { effort is only } \\
\text { carried out in } \\
\text { defined } \\
\text { structures and } \\
\text { processes }\end{array}$ \\
\hline $\begin{array}{l}\text { - Collaboration } \\
\text { Effort }\end{array}$ & $\begin{array}{l}\text { Collaboration effort } \\
\text { only on the same } \\
\text { hierarchical level }\end{array}$ & $\begin{array}{l}\text { Collaboration } \\
\text { effort through } \\
\text { the installation } \\
\text { of a feedback } \\
\text { system across } \\
\text { hierarchical } \\
\text { levels }\end{array}$ & $\begin{array}{l}\text { Collaboration } \\
\text { effort within } \\
\text { expert teams } \\
\text { in the } \\
\text { crowdsourcing } \\
\text { community. }\end{array}$ & $\begin{array}{l}\text { Close } \\
\text { collaboration } \\
\text { effort between } \\
\text { experts within } \\
\text { the ad-hoc } \\
\text { work system. }\end{array}$ \\
\hline
\end{tabular}


Figure 1*

\section{Work Organization Concept}

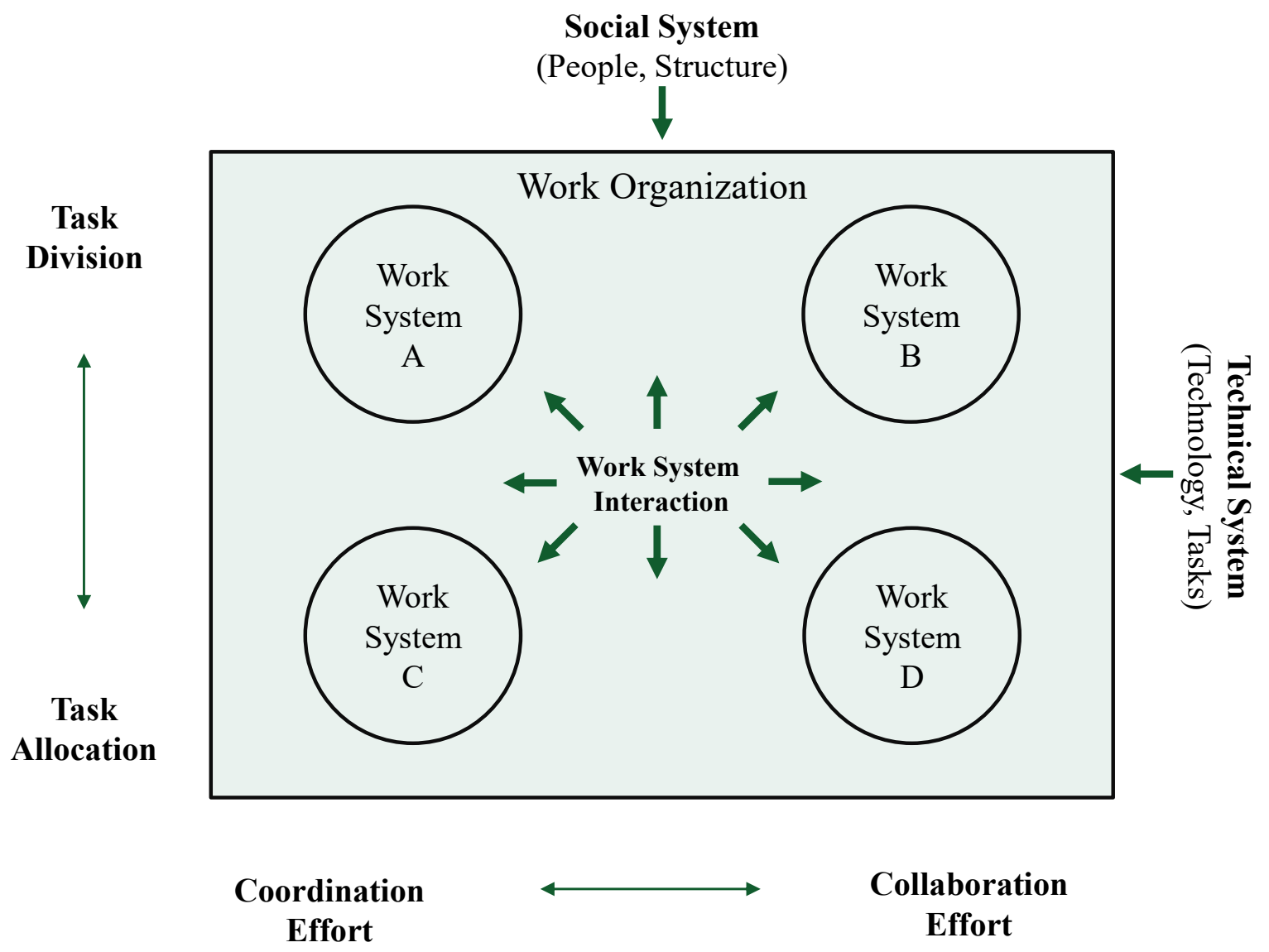


Figure 2*

Process Theory of SwissBank

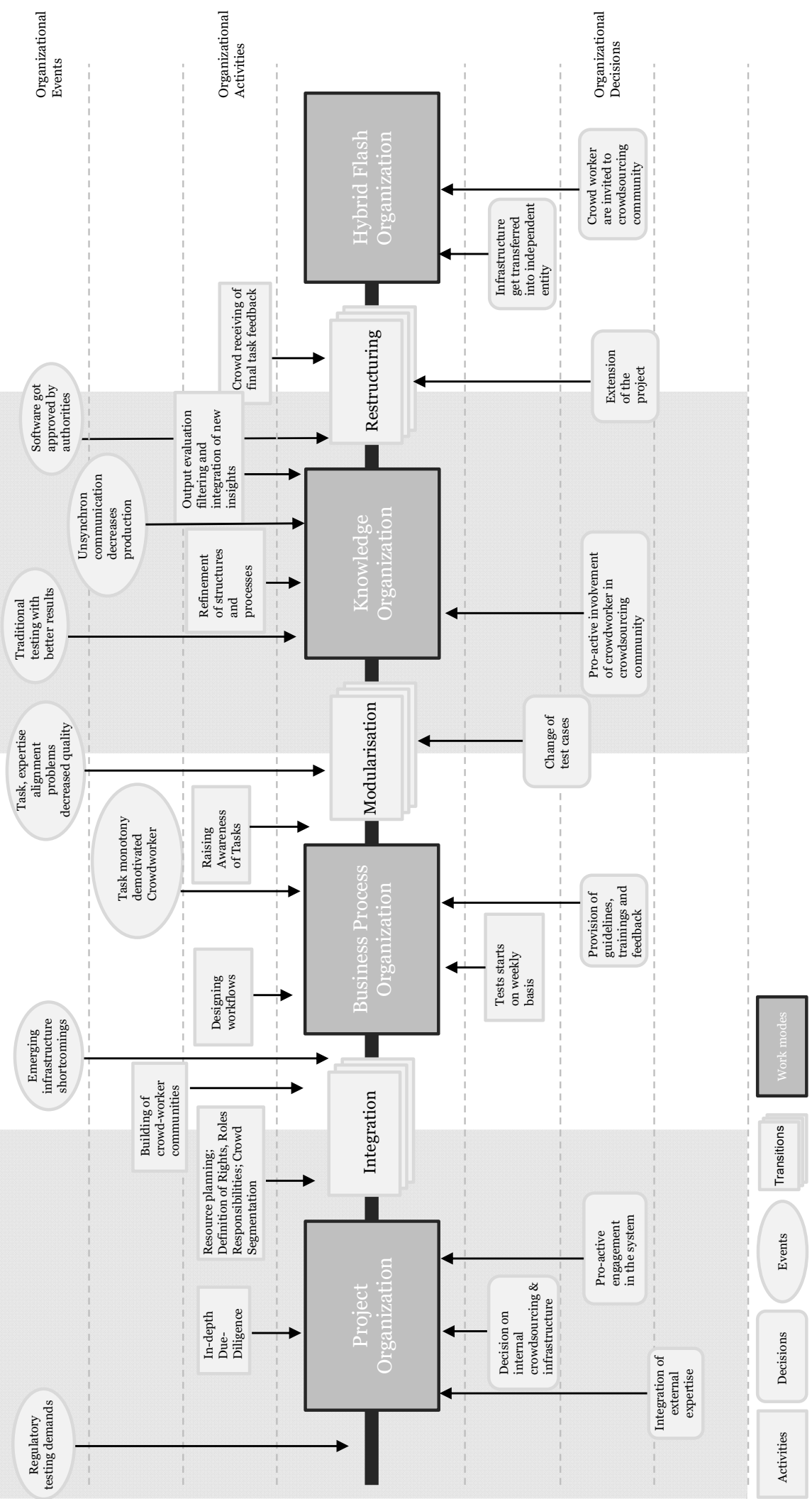

